\title{
Exploring The Development Strategy Of Cultural And Creative Tourism In Guilin: The Case Of East-West Lane
}

\author{
Zang Yunfei ${ }^{1, *}$ \\ ${ }^{1}$ College of Tourism and Landscape Architecture, Guilin University of Technology,Guilin,Guangxi,China
}

\begin{abstract}
With the development of tourism economy,cultural and creative tourism promotes the transformation of Guilin traditional tourism and also promotes the restructuring of Guilin tourism industry.This paper adopts the literature analysis method to review relevant literature, and through the analysis of development strategies and innovative research on the creative products with ethnic cultural characteristics of Guilin East-West Lane,to realize Guilin cultural and creative tourism as a new energy for the sustainable development and urban regeneration of Guilin.
\end{abstract}

\section{Introduction}

With the introduction of the policy of"Cultural Strengthening Strategy",cultural and creative industries have become hot in recent years, especially in some cities where tourism industry is the pillar,cultural and creative products have emerged in abundance.Among them, the socalled"cultural and creative"is cultural and creative products, which is a kind of new tourism industry with creativity as the core,mainly through the secondary creation of local characteristics of culture or elements through the skills and wisdom of creative people,and then form works or other forms of embodiment in line with modern aesthetics, followed by the promotion and brand marketing of cultural and creative products with the help of modern marketing means.products are promoted and brand marketing is promoted.Excellent cultural and creative products should take into account the cultural value of inducing people to think,good aesthetic form and reasonable use function, and meet the national demand for education,aesthetics and use.Cultural and creative industries play a great positive role in promoting the transformation of traditional industries, and in turn promote the transformation of new technologies for industrial restructuring, and have become a new driving force for sustainable development and urban regeneration economy.Take Xi'an as an example,Xi'an is ranked 5th in the"Cultural Construction "index, after Beijing,Shanghai,Guangzhou and Hangzhou,and official data show that the business income of Xi'an's cultural industry has been growing continuously in recent years, with a growth rate of over $20 \%$ for three consecutive years.In 2007, it exceeded 5\%, and by 2019 , the proportion had reached $6.4 \%$.As of 2020,Xi'an has 202 mass art museums and cultural centers (stations), 192 more than in 1949; 13 public libraries, 10 more; 134 museums and 424 cultural relics protection units at all levels .e.g.,Xi'an's Great Tang Dynasty City of Night,Terracotta Warriors and
Horses culture.Thus,it can be seen that the cultural and creative industry has become a new engine to promote the high-quality development of Xi'an's economy.

\section{Background Of The Study}

\subsection{The current situation of Guilin's cultural and creative industries}

Guilin,a world-renowned scenic tour city and a sacred place of wisdom for ten thousand years, is an international tourism city open to the outside world, a national tourism innovation and development pioneer area and an international tourism integrated transportation hub,as determined by the State Council.As a tourist city in Guangxi,Guangxi history,tourism,cultural heritage important city,for this profound cultural heritage and rich tourism resources can not be separated from the topography of the terrain,picturesque scenery,landscape like a fairyland on earth known as"Guilin landscape a world"reputation.Guilin is rich in tourism resources, the most representative of which,in addition to"Yangshuo",Guilin city has Jingjiang King City,Duxiu Peak,Ludi Rock scenic spot and the style of East-West Lane.East-West Lane is the only historical street left in Guilin during the Ming and Qing dynasties,with a suitable spatial scale,and is a scenic spot of Guilin's ancient historical style,containing traditional Guilin streets Zhengyang Street East Lane,Jiangnan Lane and Lanjing Lane.It embodies the historical culture of Guilin.EastWest Lane flourished as early as the Ming and Qing dynasties,and at its peak,it was also known as the"Green Dragon and White Tiger"treasure land.Here not only the great scholars and businessmen gathered and traveled,but also the distinguished officials and nobles lived here.Especially in modern times, there have been many celebrities and gentlemen who have settled here,Cen 
Chunxuan,the governor of Qing Dynasty,Long Chaoyin and Long Chaoyi, the two brothers, Wei Jichang, the former Qing dynasty scholar who was the vice mayor of Guilin after liberation, and Xie Hegang,the secretary of the famous underground party of the Communist Party of China,Bai Chongxi,all lived here.At the same time,EastWest Lane is also the birthplace of many old brands with unique local characteristics,"Yixuan"Guilin rice noodles,"Zhang Yongfa"cloth-dyeing workshop,"Cao Baoyuan"pills and pills."Xiong Tonghe"pharmacy,"Jufengtai"trading

house,"Youxin"trading house,"Huang Changdian"brush and The"Hong Qing Long"mooncake.all originated from here. Therefore,the East-West Lane Historical and Cultural Commercial Street,as an important part of Guilin's famous historical and cultural city,is based on the main functions of traditional residence,traditional commerce,cultural experience,leisure tourism.and integrates scenic tour appreciation, with the characteristics of"city streets and lanes,celebrity mansions",while reflecting the development of the times of multi-cultural and composite historical style area.The main purpose in creating the most characteristic historical and cultural district in Guilin. The development of unique cultural and creative products of Guilin East-West Lane is of great significance in creating the characteristic cultural tourism of East-West Lane.

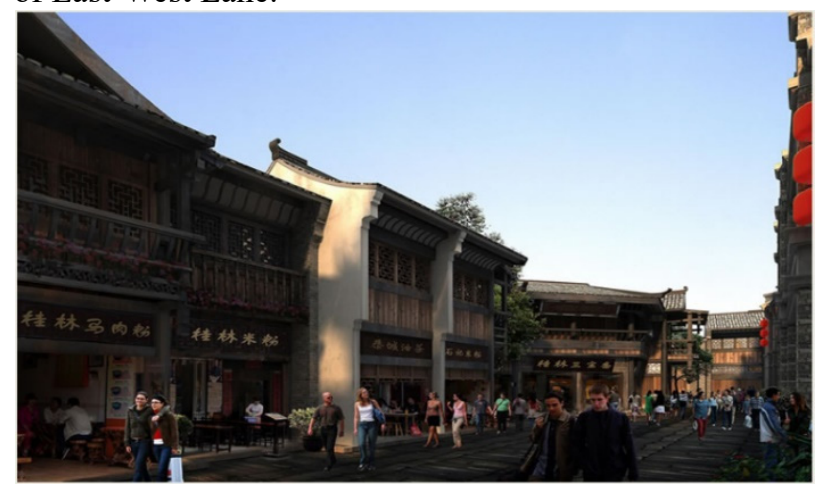

\subsection{Current situation of cultural and creative products for tourism in outstanding cities}

In the background of the development of cultural industry like hot tea,a number of cities with good status and remarkable effect of cultural and creative industry have emerged in China.These cities are able to start from their own characteristic culture,make use of local conditions,inject emotion and creativity,so that cultural and creative products are no longer uniform, here two cities,Beijing and Chengdu,are taken as examples for analysis.Since Beijing proposed the development of cultural and creative industries in 2006, the added value of cultural and creative industries has been maintaining a high growth rate.As the political,economic,cultural and educational center of the country, it is also the city with the largest number of world cultural heritage in China,rich in tourism resources, and the annual tourist reception of the Forbidden City alone exceeded 1.6 billion in 2017, the huge group of tourists has laid a good foundation for the development of tourism and cultural and creative industries in Beijing It attaches importance to the promotion of traditional culture and highlights the inheritance of cultural veins, especially the excavation of royal culture,hutong culture and Forbidden City culture, while the development of cultural creative products focuses on combining elements of cultural relics in the collection,stories of cultural relics, highlighting the exclusive character of the Forbidden City's cultural creations,starting from cultural symbols such as palace life,architecture,home,costumes and accessories to refine the"the dynasty bead headphones"'top hat umbrella"'I am such a Hanzi"'folding fan,"Yin Zhen cultivation and weaving map notepad"The reality show"New,Forbidden City",which was broadcasted in 2018, has pushed the Forbidden City's creative fever to a new climax.

At the same time,Chengdu,also a famous historical and cultural city,brought together 23,500 exhibits from more than 760 creative design institutions from 30 countries and regions at the 5th Chengdu Creative Design Week held in November 2018 with the theme of"Creative Chengdu,Better Life".The development of cultural and creative products has been integrated into the clothing,food,housing and transportation of the nationals, from agricultural and sideline products to hightech products,all branded with a strong Sichuan flavor,and there are hundreds of cultural and creative products with panda as the element alone.In addition,there are hundreds of cultural and creative products with panda elements alone.In addition,there are also not a few of Kuanzhai Alley,Chunxi Road,Koi,Giant Panda Base.The Dongjiao Memory Creative Park has also become a net red card base, and a ballad"Chengdu,Chengdu"has made the originally quiet Yulin Road lively.In a comprehensive view,Chengdu's tourism cultural and creative industry is mainly based on three creative elements,namely Chengdu cuisine,Sichuan opera face changing and giant panda image,combined with hot topics and modern technology for innovation.

\section{Problems Faced By Cultural And Creative Products}

\subsection{There is homogenization of products and no innovation}

Cultural creative products are a new creative way covering design level in all aspects, and no longer a single form of design.However,many people simply confine cultural creative products to one kind of field,pillows, bookmarks and many other small products.For these cultural creative products, they are not easy to be found and noticed by everyone in today's environment of rapid development of the design industry,and will be buried in the flood of the whole era.Therefore,innovation is the most important problem facing cultural creative products at present, and with innovation there is room for survival and a broad market prospect for tourism,so innovation is the most important reason.Guilin's cultural and creative industry has been developing rapidly in the past few years, but many cultural and creative design products have a lot of the same points and are constantly imitating and repeating previous ideas, without much substantial innovation points 
appearing,resulting in Guilin's cultural and creative industry being lukewarm in recent years.At the same time,it also reflects a trend in the development of China's tourism industry.Now that industrialization is complete, the phenomenon of winner takes all in many fields within the cultural and creative industry,and products that can be mass-produced will squeeze the original market,leading to homogenization.Therefore,the small capital cultural and creative enterprises that have not yet become large-scale can only put the point of difference on the service.Obviously, there is still room for substantial improvement in many cultural and creative tourism in East-West Lane,Guilin (as shown in Table 1).

Table1. Influence analysis of the development elements of

\begin{tabular}{|c|c|c|c|c|c|c|c|}
\hline \multicolumn{8}{|c|}{ Guilin's tourism culture and creative industry } \\
\hline title & $\begin{array}{l}\text { very } \\
\text { poor }\end{array}$ & poor & $\begin{array}{l}\text { gen } \\
\text { eral }\end{array}$ & good & $\begin{array}{l}\text { Very } \\
\text { good }\end{array}$ & $\begin{array}{c}\text { Ver } \\
\text { y } \\
\text { well }\end{array}$ & $\begin{array}{l}\text { Do not } \\
\text { know } \\
\text { much } \\
\text { about }\end{array}$ \\
\hline $\begin{array}{l}\text { Government } \\
\text { support }\end{array}$ & 82 & 269 & 144 & 123 & 160 & 94 & 92 \\
\hline $\begin{array}{c}\text { Overall creative } \\
\text { ability }\end{array}$ & 75 & 267 & 138 & 148 & 154 & 67 & 115 \\
\hline Product added & 54 & 118 & 169 & 155 & 126 & 112 & 83 \\
\hline $\begin{array}{l}\text { value } \\
\text { Attraction of } \\
\text { tourism projects }\end{array}$ & 263 & 318 & 146 & 177 & 118 & 101 & 82 \\
\hline Industrial market & 72 & 239 & 132 & 173 & 123 & 117 & 108 \\
\hline $\begin{array}{l}\text { Effect of } \\
\text { publicity }\end{array}$ & 284 & 83 & 164 & 136 & 129 & 100 & 68 \\
\hline
\end{tabular}

When designing cultural and creative products, we should always take the design concept of promoting traditional culture as the key support point of the cultural and creative product design,always keep the design theme of culture, and take the promotion of Guilin traditional culture as the design entry point.In the design method,the choice of materials to find a breakthrough point and innovation point,break the inherent design thinking,can choose many different materials of design materials, the pursuit of the design of the most original traditional minority cultural connotation.At the same time, it is also necessary to take into account the aesthetics of the design and accurately understand the modern market demand,so that the viewer has both spiritual sensitization and visual enjoyment.

\subsection{Incomplete understanding of product demand,no marketability}

The first thing to consider in designing any product is the consumer,understanding the consumer's feelings and preferences is an important prerequisite for making all cultural and creative products.Patrick Newber,the author of"Experience Design",said that"there are intangible,tangible and expected values",in which he pointed out that"the seller has what the buyer expects,which is the inherent law of value itself".Consumers generally suggest to increase the variety of cultural and creative tourism products,improve the connotation of cultural and creative tourism products,reflect the regional characteristics of Guilin, and enhance the promotion. The highest level of unwanted expectation is"reflect regional characteristics",while"increase cultural connotation"indicates that more nationals are expecting Guilin cultural and creative characteristics of ethnic culture ${ }^{[7]}$ (as shown in Table 2).

Table2. Proportional analysis of consumers' expectation level for the development of cultural and creative tourism

\begin{tabular}{|c|c|c|c|c|}
\hline rating & $\begin{array}{l}\text { oduct } \\
\text { Don't } \\
\text { need }\end{array}$ & $\begin{array}{c}\text { Guili1 } \\
\text { It will } \\
\text { take }\end{array}$ & $\begin{array}{l}\text { Need to } \\
\text { be }\end{array}$ & $\begin{array}{l}\text { Very } \\
\text { need }\end{array}$ \\
\hline $\begin{array}{l}\text { Increase cultural } \\
\text { connotation }\end{array}$ & 123 & 82 & 179 & 214 \\
\hline Increase product range & 87 & 296 & 219 & 155 \\
\hline $\begin{array}{l}\text { Reflect regional } \\
\text { characteristics }\end{array}$ & 253 & 118 & 174 & 173 \\
\hline Marketing efforts & 90 & 318 & 200 & 137 \\
\hline
\end{tabular}

The main thing is to let consumers feel the profound traditional ethnic culture of Guilin,deeply experience the cultural atmosphere of Guilin as a tourist city,and at the same time make consumers get spiritual comfort and spiritual baptism,but most of the cultural and creative products on the market now lack originality,so that consumers feel that Guilin cultural and creative products are all the same,lacking in design Connotation,lack of communication and communication with consumers deep in their hearts.

\section{Development Strategy Of Cultural And Creative Product Design}

From the perspective of tourists' demand for Guilin's cultural and creative tourism,tourists are no longer satisfied with the traditional form and content of sightseeing,and the demand for diversity,entertainment,symbolism,practicality and virtualization gradually becomes an important feature of"self-development"in the process of cultural and creative tourism experience.Among the cultural industry categories,"news and information services","content creation and production","creative design services","cultural communication channels","cultural investment and operation","cultural auxiliary production and intermediary services","cultural equipment production"and"cultural consumption terminal production"."cultural consumption terminal production"and other categories,mostly cross-fertilized with the six industrial elements of the tourism industry.This phenomenon shows that the tourism industry and the cultural industry are mutually exclusive, and there is no such thing as a"fusion"relationship, as cultural creativity and experience consumption are inherent properties of the tourism industry itself.Tourism culture and innovation industry includes scenic spots,accommodation,catering,transportation,shopping,en tertainment,recreation, leisure and other new forms of 
tourism with cultural and creative connotations (as shown in Figure 1).

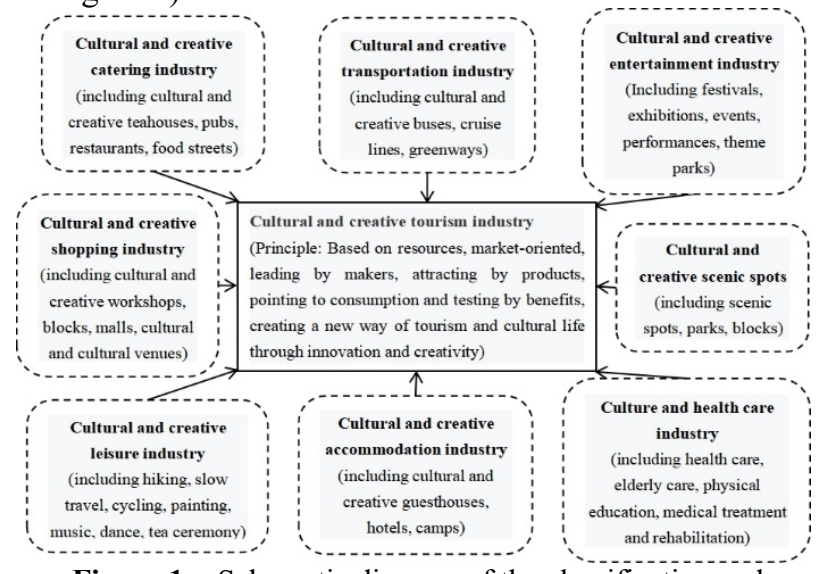

Figure 1. Schematic diagram of the classification and structural system of tourism cultural and creative industry elements

\subsection{The design of cultural and creative products forms the scale}

Cultural creative products refer to taking local traditional culture as creative elements,combining regional characteristics and theoretical knowledge of disciplines, and through innovative design, giving different carriers a new cultural face to present,through the combination of culture and products,so that the goods have the value of the goods themselves, but also increase the added value of traditional characteristics of culture,so that the local traditional culture has been greatly promoted,which is also in line with the current society actively This is also in line with the creative economy development mode advocated by the society nowadays.At present,Guilin's cultural and creative industry is still in the development exploration period,many cultural and creative products are still immature, the understanding of traditional culture is unclear,the combination of products and culture is still abrupt,no large-scale industrial chain has been formed,and an integrated industrial chain of design,production,packaging and sales should be gradually improved,and the platform and channels for product promotion and sales should be guaranteed.At the same time,talents are also an indispensable and important factor in the cultural and creative industry. The lack of talents is the main factor restricting the development of creative cultural products.

In the golden period of Guilin's rapid economic development, the creative economy oriented by traditional culture of Guilin East-West Lane is flourishing.The creative economy is an important factor indispensable to the transformation of Guilin's economic development, and it is necessary to gradually establish and improve the selection mechanism and management mode of creative design talents, establish an excellent design talent team, and provide a talent guarantee basis for the development and growth of cultural and creative industries, Guilin East-West Lane culture The upgrading of creative products has promoted the vigorous development of creative economy,and now the cultural and creative products are developing in the direction of a kind of large- scale cultural and creative industry, in which the Guilin municipal government plays a great role, and creates a good development mode of creative economy while it has to promote the development of Guilin's cultural and creative industry with great force.

\subsection{The design of cultural creative products should be elitist and diversified}

Guilin's national traditional culture is ancient and longstanding,and has left countless precious treasures in the course of time.However,due to the influence of tourism in recent years, Guilin has accepted a lot of western culture, and the invasion of foreign culture is a huge impact on our traditional national culture,more nationals believe and esteem foreign culture,and never really understand and discover the traditional national culture that Guilin has developed and evolved for thousands of years. Therefore, cultural and creative products can be the breakthrough point,taking material products as the carrier,promoting traditional national culture as the cornerstone and adding humanistic emotion as the support,which is the art expression form urgently needed by the society at present.

At the same time,cultural and creative tourism attaches more importance to the tourist's spiritual experience in the process of tourism,not only the traditional sensory experience,but also a kind of material psychological satisfaction,which is also the inevitable trend of tourism consumption in China's economic era,emphasizing the tourist's participation,interaction and integration as well as psychological perception,and emphasizing the tourist's understanding and penetration of Guilin's culture,history,life and customs.Guilin East-West Lane has a lot of historical stories background,by digging deeper behind the historical stories, to create cultural and creative design experience tourism,can raise the historical heritage of East-West Lane to another level,distinguished from the already famous Yangshuo West Street,the two echo,can greatly complement the deep cultural heritage of downtown Guilin.Therefore, when developing the cultural and creative industry of Guilin East-West Lane,we should be based on today and look to the future,accept and learn more advanced design concepts with a more open attitude,push the boundaries,actively understand the most cutting-edge design concepts of fashion,keep up with the promulgation and implementation of national policies,always adhere to the principle of innovation, and strive to maximize the cultural value and commercial value of cultural and creative products.

\subsection{The design of cultural and creative products presents family sentiment}

Cultural and creative products are products that follow the development trend of the times and have strong development potential.Nowadays,many exhibition halls,museums,coffee shops and other places in Guilin have cultural creative products, which have been deeply rooted in our lives and are inseparable from our lives.In the cultural and creative product design,cultural symbols 
are the core of the cultural and creative product design,it is not simply the decoration of the cultural and creative products, but the reference of the national cultural characteristics of Guilin East and West Lane,which is the difference between the cultural and creative products and the general products.After fully understanding the traditional national culture to be used in the design,we can discover the unique sentiment of consumers towards the national traditional culture, and make the cultural and creative products that directly hit the consumers The cultural and creative products can only be made to hit consumers' hearts.Cultural dress product design to use the appropriate way to make consumers feel the connotation of cultural and creative products, focusing on the communication between people and products, not only on the product itself to show the excellent Guilin East West Lane traditional culture,in the way to show the finished product design of cultural and creative products can also be used to Guilin traditional national culture,for example: you can use Guilin East West Lane to create painful old origin of the excellent traditional cultural forms to present cultural and creative products, leaving an extremely deep impression on consumers, and also generating deep memory points,so that consumers have a greater sense of identification with our national culture.Cultural and creative products are a kind of consumers' feelings for home, and through cultural and creative products they find the sentiment of the country or feel the colorful and excellent Chinese culture from it.Therefore,cultural and creative products are a professional field with great research value.

\section{Conclusion}

Economic globalization has not only brought China unprecedented development opportunities, but also given rise to inevitable problems. The cultural invasion has challenged the traditional Chinese culture, which has been developed for thousands of years, like never before,so we put forward cultural self-confidence.The design of the products,both conceptually and formally,reflect the strong self-confidence of Guilin national culture,inherit and carry forward the profound traditional culture of the nation, and on the basis of inheritance continue to push forward,creating excellent cultural and creative products that not only promote China's excellent traditional culture,but also respond to the development of the times and thus promote the development of cultural and creative tourism.At the same time,tourists' demand for tourism is more and more inclined to experience and seek differences, and the cultural and creative tourism of EastWest Lane is in line with tourists' pursuit of spiritual culture, and the cultural and creative tourism market has great potential.However,there are still outstanding problems in the design of cultural and creative products,such as homogenization of products,insufficient understanding of market demand and no innovation. Therefore, Guilin cultural and creative industry still needs to conduct innovative research on the design of Guilin cultural and creative products according to the requirements of China's big time development,so that the cultural and creative products can be more innovative and vital,and inject new vitality into the development of China's cultural and creative tourism.

\section{References}

1. Return to manufacturing: Blue Book on the Development of Xi'an International Metropolis (2020) [R].Shanxi,Xi'an:,(2020)

2. The Institute of Archaeology of the Chinese Academy of Social Sciences inaugurated the"sacred place of wisdom for ten thousand years"for Guilin [R].Guangxi,Guilin:,(2018)

3. Guilin will renovate Zhengyang East-West Lane [N]. Guangxi,Guilin; South China Morning Post,(2013)

4. East-West Lane Cultural District Introduction[EB/OL].http://www.dongxixiang.com.c n/about/aboutus.html,(2015)

5. Zhang Bo,Fan Hongyu,Li Shitian.Exploration of urban tourism cultural and creative product development--Jinan as an example[J].Think Tank Times,16:119-120.(2019)

6. Wu Yifan,Yin Yaoyao.Problems and development trend in cultural creative product design[J].Art Sea,05:82-84.(2019)

7. Ren Xiaoqi.Research on the development of tourism cultural and creative industry in Yansan District,Guilin City[D].Guilin University of Technology,(2019)

8. Jiang Jun.Analysis of the inheritance and protection of vernacular architecture[J].Building Materials and Decoration,47:73-74.(2017) 